\title{
Continuous versus pulsating flow boiling. Experimental comparison, visualization, and
} statistical analysis

Kærn, Martin Ryhl; Elmegaard, Brian; Meyer, Knud Erik; Palm, Björn; Holst, Jørgen

Published in:

Science and Technology for the Built Environment

Link to article, DOI:

$10.1080 / 23744731.2017 .1319667$

Publication date:

2017

Document Version

Peer reviewed version

Link back to DTU Orbit

Citation (APA):

Kærn, M. R., Elmegaard, B., Meyer, K. E., Palm, B., \& Holst, J. (2017). Continuous versus pulsating flow boiling. Experimental comparison, visualization, and statistical analysis. Science and Technology for the Built Environment, 23, 983-996. https://doi.org/10.1080/23744731.2017.1319667

\section{General rights}

Copyright and moral rights for the publications made accessible in the public portal are retained by the authors and/or other copyright owners and it is a condition of accessing publications that users recognise and abide by the legal requirements associated with these rights.

- Users may download and print one copy of any publication from the public portal for the purpose of private study or research.

- You may not further distribute the material or use it for any profit-making activity or commercial gain

- You may freely distribute the URL identifying the publication in the public portal 


\title{
Continuous vs. pulsating flow boiling. Experimental comparison, visualization and statistical analysis
}

\author{
MARTIN RYHL KÆRN ${ }^{1}$, BRIAN ELMEGAARD ${ }^{1}$, KNUD ERIK MEYER ${ }^{1}$, BJÖRN \\ PALM $^{2}$, JØRGEN HOLST ${ }^{3}$ \\ ${ }^{1}$ Department of Mechanical Engineering, Technical University of Denmark, Kongens Lyngby, Denmark, \\ ${ }^{2}$ Department of Energy Technology, Royal Institute of Technology, Stockholm, Sweden \\ ${ }^{3}$ Danfoss Drives A/S, Gråsten, Denmark
}

This experimental study investigates an active method for flow boiling heat transfer enhancement by means of fluid flow pulsation. The hypothesis is that pulsations increase the flow boiling heat transfer by means of better bulk fluid mixing, increased wall wetting and flow-regime destabilization. The fluid pulsations are introduced by a flow modulating expansion device and are compared with continuous flow by a stepper-motor expansion valve in terms of time-averaged heat transfer coefficient. The cycle time ranges from $1 s$ to 9 for the pulsations. The time-averaged heat transfer coefficients are reduced from transient measurements immediately downstream of the expansion valves at low vapor qualities. The results show that the pulsations improve the time-averaged heat transfer coefficient by $3.2 \%$ on average at low cycle time (1 s to $2 \mathrm{~s}$ ), whereas the pulsations may reduce the time-averaged heat transfer coefficient by as much as $8 \%$ at high heat flux $\left(q \geq 35 \mathrm{~kW} / \mathrm{m}^{2}\right)$ and cycle time $(8 \mathrm{~s})$. The latter reduction is attributed to a significant dryout that occurs when the flow modulating expansion valve is closed. Additionally, the effect of fluid flow pulsations is found to be statistically significant, disregarding the lowest heat flux measurements.

\section{Introduction}

High heat exchanger performance is crucial to meet efficiency standards with low cost and environmental impact in various applications such as heat pumps, refrigeration and air-conditioning. The performance of heat exchangers may be improved by passive and active heat transfer enhancement techniques applicable to air, liquid and phase change heat exchangers. In the current paper, an experimental investigation of flow boiling heat transfer is conducted in a traditional round-tube evaporator with the aim of heat transfer enhancement by means of fluid flow pulsations. The pulsations are generated by a flow- 
modulating expansion valve (EXV). The refrigerant is chosen to be R134a, i.e. a well-examined pure fluid with respect to steady continuous flow boiling heat transfer measurements.

The field of heat transfer enhancement is enormous in the literature and many reviews have been given in even small narrow subjects. Some examples of more broad reviews on various heat transfer enhancement techniques are the reviews given by Bergles (2003) and Ohadi et al. (1996). They indicated that fluid pulsation (or fluid vibration as denoted by these authors) had received little attention at that time in the literature for boiling and condensation enhancement, and that the results had not been promising so far. Antonenko et al. (1992) found that the developed nucleate boiling region was impossible to enhance by fluid vibrations at $15 \mathrm{~Hz}$ to $100 \mathrm{~Hz}$. They argued that the superheated layer near the wall was destroyed which led to the suppression of the bubble formation. However, in other modes of heat transfer, like convective heat transfer and film boiling, enhancement was as much as $50 \%$. Obinelo et al. (1994) studied steam pulsations $(0.08 \mathrm{~Hz}$ to $0.25 \mathrm{~Hz})$ in a reflux condenser and found that the induced pulsations had a destabilizing effect on the water column and led to a several-fold increase in the condensation capacity.

Bohdal and Kuczyński (2005) investigated flow oscillations in an R134a evaporator coil. The periodically generated disturbances were created by a flow-modulating valve with a constant opening time at $5 \mathrm{~s}$ and closing times from $5 \mathrm{~s}$ to $30 \mathrm{~s}$ (cycle times: $10 \mathrm{~s}$ to $35 \mathrm{~s}$ ). They found that the superheated region increases with the cycle time and leads to a decrease in the heat transfer performance. Later, the same authors (Kuczyski et al. 2012) investigated flow oscillation during condensation of R134a in pipe mini-channels with $0.64 \mathrm{~mm}$ to $3.3 \mathrm{~mm}$ diameter. The cycle times were lower compared to the earlier study. It ranged from 0.2 $\mathrm{s}$ to $4 \mathrm{~s}$ with equal opening and closing times. They found that the subcooling area in the condenser increased with increasing cycle time, while the condensation area decreased and led to a reduction of the overall condenser effectiveness.

Chen et al. (2010) studied time-periodic flow boiling of R134a in a narrow annular duct with 2 mm gap. The imposed mass flow oscillations were nearly triangular waves with peak-to-peak amplitudes from $10 \%$ to $30 \%$ of the average flow and cycle times from $30 \mathrm{~s}$ to $120 \mathrm{~s}$. Only a slight impact on the time-averaged heat transfer coefficient and boiling curve was observed at these modest oscillations. Roh and Kim (2012) conducted an experimental study on the system performance enhancement of a R410A heat pump using an 
additional solenoid-driven expansion valve in parallel with the main expansion valve. The additional expansion valve was periodically opened for only $200 \mathrm{~ms}$ at cycle times ranging from $5 \mathrm{~s}$ to $200 \mathrm{~s}$. The coefficient of performance (COP) was improved by up to $4 \%$. The authors suggested the enhancement was caused by both the pulsation enhanced heat transfer and the so-called "pushing effect" that elevated the compressor suction and discharge pressures immediately after each pulse, thereby reducing the compression ratio.

Various forms of dynamic two-phase flow instability have been recognized in the literature (Ruspini et al. 2014), and they should be mentioned in relation to the current investigation, although these occur in the nuclear industry where only the liquid and two-phase regions are present in the evaporator. The two major modes of these dynamic oscillations are density-wave type (high frequency) and pressure-drop type (low frequency) oscillation. The former is caused by the dynamic interaction between pressure drop, flow rate and local density variation, and is characterized by large variations in outlet vapor quality and mass flow rate. The latter is caused by the S-shape pressure drop vs. mass flow rate characteristics of two-phase flow systems, and will occur specifically when a compressible volume is located upstream or distributed within the boiling channel. These oscillations are not expected to occur in dry-expansion systems with superheated vapor generation. In these systems, a well-known phenomenon called hunting is sometimes encountered if a thermostatic expansion valve is used. Even in steady operation, the transition point from two-phase to vapor phase oscillates (Wedekind, 1971), resulting in oscillation of superheat and thus valve opening degree. Even for electronic expansion valves, a minimum degree of superheat must be ensured for a stable superheat signal and system operation.

The objective of the current paper is to demonstrate the possible heat transfer enhancement with flow pulsations, by comparing the pulsating flow boiling heat transfer results with that of continuous flow boiling for low qualities, i.e. immediately downstream of the pulsation source with apparently the strongest pulsation strength. The oscillating dry-out location and associated effects on the heat transfer performance is not considered herein. The hypothesis is that the pulsations will increase the flow boiling heat transfer by means of better bulk fluid mixing, increased wall wetting and flow-regime destabilization. Two widely accepted flow-boiling mechanisms occur in traditional tubing, namely the nucleate and the convective boiling. The concept of fluid flow pulsation is evidently linked to both these mechanisms. The convective boiling term is 
believed to be enhanced due to fluid pulsation, while the nucleate boiling is believed to decrease due to increased suppression. For example as the valve opens, more refrigerant will travel downstream with higher mass flux, thereby changing flow regime from e.g. stratified-wavy to annular, thus wetting the wall surface better. On the other hand, the higher mass flux the more suppression of nucleate boiling.

The paper includes a description of the experimental apparatus, including the data reduction method and uncertainty analysis, as well as a single-phase heat transfer comparison. Then the experimental design is introduced and illustrated for both the continuous and pulsating flow. The results are presented using two approaches: a direct comparison in each measurement location, and a comparison using response surfaces that includes statistical significance. Both approaches deal in different ways with the challenge that the vapor quality and the heat flux are interdependent and simultaneous outputs of each experimental run. Additionally, the flow pulsations are visualized immediately after the expansion valve (before the test section) and after the test section. Finally, the results are discussed and followed up by the conclusions.

\section{Experimental apparatus}

The experimental apparatus is illustrated in Figure 1. It consists of a pump bypass loop from which a small amount of refrigerant is circulated through the test section. The pump bypass loop circulates at least 5 times the refrigerant needed for the test-section. The stepper motor bypass valve controls the high-pressure liquid extracted to the test section, whereas the low pressure is controlled by an oversized condenser, and accordingly the temperature of the refrigerated ethylene-glycol/water mixture (35/65\%). The high-pressure liquid $\left(T_{\text {sat }}=32^{\circ} \mathrm{C}\right)$ that is extracted to the test section is led through a Siemens SITRANS FC300 Coriolistype mass flow meter with an accuracy of $0.14 \%$ and heated to $30{ }^{\circ} \mathrm{C}$ by an oversized liquid water heater. To avoid spurious oscillating mass flow readings, two pulsation dampers are installed both upstream and downstream of the mass flow meter. The subcooled liquid is expanded down to low-pressure two-phase flow $\left(T_{\text {sat }}=5{ }^{\circ} \mathrm{C}\right)$ by exchangeable expansion valves, namely the flow modulating EXV (Danfoss AKV) and the stepper-motor EXV (Danfoss ETS). Two $200 \mathrm{~mm}$ long glass-tube-sections with external vacuum champers are installed upstream and downstream the test section to visualize the flow with high-speed camera. The upstream glass section is located about $120 \mathrm{~mm}$ downstream of the throat areas in the EXV. The remaining liquid is evaporated in an auxiliary evaporator and led back to the pump bypass. 
Figure 1

The evaporator test-section is sketched in Figure 2 including temperature and pressure sensors. It is a co-axial type evaporator with refrigerant R134a flowing in the inner tube and distilled water flowing outside helically through four sub-sections, and allows computing four heat transfer coefficients for each steady state reading. We use hot water instead of electrical heat to heat-up the evaporator for the following reason: The liquid dry-out of the inner wall surface would increase the wall temperature rapidly, if electrical heaters were used, and possibly reach unpractical temperatures in typical evaporators, when the flow modulation valve is closed. On the contrary, the wall temperature will always be limited by the hot water temperature, when hot water is used.

Figure 2

The inner copper tube internal and external diameters were $8 \mathrm{~mm}$ and $10 \mathrm{~mm}$, respectively, and the outer tube inner diameter was $14 \mathrm{~mm}$. The water was led away from the annulus and through PTFE static mixers in order to measure a well-mixed average temperature before entering the next sub-section. The helical flow was arranged by folding a $2 \mathrm{~mm}$ capillary copper tube in a spiral shape before inserting it into the outer transparent acrylic tube during assembly and ensured an even helical angle specified to 30 degrees. The transparent outer tube allowed for a visual inspection of air bubbles before the measurements were recorded. Wall temperatures were measured externally at the top and bottom of the inner tube in the center of each subsection by soldering $0.5 \mathrm{~mm}$ sheathed thermocouples (Omega Engineering type-T with special limits of error) into $10 \mathrm{~mm}$ grooves along the tube. Special attention was given to avoid any additional thermal capacitance in contact with the inner tube wall in the current design in order to capture wall temperature oscillation due to flow pulsation. Only small parts in the test section (e.g. o-rings) were allowed to be in contact with the inner tube and all connecting blocks were made of PVC. The capillary tube had a small mass and small contact area with the inner tube too. Saturation pressures and temperatures were measured upstream and downstream the test-section. The cold junctions of the thermocouples were installed into an ice-point 
reference and the hot junction readings were calibrated against a standard resistance thermometer using a calibration bath to an accuracy of $0.031 \mathrm{~K}(2 \times$ standard deviation) before installation. The temperature readings were performed by National Instruments CompactDAQ module 9214 configured in high-speed mode in order to resolve the temperature transients due to flow pulsation. It resulted in a poorer single sample accuracy $(0.1 \mathrm{~K})$ due to the increased sensitivity of measuring in high-speed mode. All thermocouples were recorded at $10 \mathrm{~Hz}$. The pressure transmitters were also calibrated using a dead-weight tester and found to have a hysteresis within $150 \mathrm{~Pa}$ and an accuracy of $0.081 \%$ FS ( 6 bar) and $0.091 \%$ FS (10 bar) for the low and high-pressure transmitters, respectively. National Instruments CompactDAQ module 9203 was used to read both refrigerant mass flow and pressure at $1000 \mathrm{~Hz}$. The water flow rates were measured by an ovalgear volume flow meter with an accuracy of $0.26 \%$ FS $(1 \mathrm{~L} / \mathrm{min})$ and read by National Instruments CompactDAQ module 9411.

\section{Data reduction}

The data reduction is similar to the method used by Wojtan et al. (2005). It is based on a regression of the time-averaged water flow enthalpies, which allows for the time-averaged local heat flux evaluation by differentiation.

$$
q(z)=\frac{\rho_{w} \dot{V}_{w}}{\pi d} \frac{\mathrm{d} h_{w}}{\mathrm{~d} z}-q_{\infty}
$$

where $\rho_{w}, h_{w}$ and $\dot{V}_{w}$ are the density, specific enthalpy and volume flow rate of water, $d$ is the inner tube internal diameter and $q_{\infty}$ is the sub-section averaged heat loss/gain through the outer insulation. This value was always calculated to be below $2 \mathrm{~W}$. We found the best regression of the water flow enthalpies by using the following power based form:

$$
h_{w}=a(z+b)^{c}
$$

where $\mathrm{a}, \mathrm{b}$ and $\mathrm{c}$ are coefficients of the regression. The heat transfer coefficient is finally computed by

$$
\frac{1}{\alpha(z)}=\frac{T_{\mathrm{wall}}-T_{\mathrm{sat}}}{q(z)}-\frac{\ln (D / d) d}{2 k}
$$

where $T_{\text {sat }}$ is the saturation temperature evaluated by the measured time-averaged saturation pressure, $T_{\text {wall }}$ is the time-averaged wall temperature, $D$ is the outer diameter and $k$ is the thermal conductivity of the copper tube. The local time-averaged vapor quality is computed by integrating the energy balance across the tube 


$$
x(z)=x_{\mathrm{in}}+\frac{\rho_{w} \dot{V}_{w}}{h_{\mathrm{fg}}} \int_{0}^{z} \frac{\mathrm{d} h_{w}}{\mathrm{~d} z} \mathrm{~d} z
$$

where $h_{\mathrm{fg}}$ is the enthalpy of evaporation and $x_{\mathrm{in}}$ is the inlet vapor quality to the test section (computed by the measured pressure and temperature of the liquid before the EXV assuming isenthalpic expansion).

\section{Uncertainty}

Table 1 summarizes the absolute and relative single sample uncertainties using the error propagation method by Kline and McClintock (1953) as well as variable range of the reduced variables from Equation 1, 3 and 4 . Note that the data from test sub-section 1 are omitted throughout the paper, because one of the wall temperature sensors was broken during installation. The absolute uncertainty ranged from (54 to 143 ) W/m² $\mathrm{K}$ and (141 to 390$) \mathrm{W} / \mathrm{m}^{2}$ for the heat transfer coefficient and heat flux, respectively. Percentagewise, the uncertainty became as much as $10 \%$ for small values of heat flux and heat transfer coefficient. Above 2 $\mathrm{kW} / \mathrm{m}^{2} \mathrm{~K}$, the heat transfer coefficient predictions had uncertainties below $3.8 \%$ (corresponding to $69 \%$ of the data). The absolute error in the local vapor quality calculations was always below 0.006 .

Table 1

\section{Single-phase heat transfer}

Liquid-liquid tests were also conducted in the test-section to ensure the reliability of the measurements and data reduction method. These reduced Nusselt numbers are compared in Figure 3 with the single phase correlation by Gnielinski (1976) at Reynolds numbers from 3800 to 6100 (including data points at Re $\sim 8000$, i.e. fully open EXV). The comparison resulted in a mean absolute deviation (MAD) and a mean relative deviation of (4.6 and -0.2) \%, respectively, where the MAD and MRD are given by

$$
\begin{aligned}
\text { MAD } & =\frac{1}{N} \sum_{i=1}^{N}\left|\frac{\alpha(i)_{\text {pred }}-\alpha(i)_{\exp }}{\alpha(i)_{\exp }}\right| \\
\text { MRD } & =\frac{1}{N} \sum_{i=1}^{N}\left(\frac{\alpha(i)_{\text {pred }}-\alpha(i)_{\exp }}{\alpha(i)_{\exp }}\right)
\end{aligned}
$$


The comparison indicates a good agreement and thus reliable measurements and data reduction method. The single-phase tests also revealed that the solenoid-driven flow-modulating valve released a nearly constant heat input of $6 \mathrm{~W}$ at $100 \%$ opening degree for all refrigerant flow rates. Ideally, the stepper-motor should not draw any current in a given steady state.

Figure 3

\section{Experimental Design}

Response surface methodology was used to generate the experimental design and to process the data with the aim of clarifying whether the effect of the pulsations is statistically significant. The response surface methodology was performed with the software Design Expert 8 (2010). Both refrigerant and water inlet states are kept constant in all of the experimental runs. The inlet refrigerant state results from the fixed saturation temperature $\left(T_{\text {sat }}=5{ }^{\circ} \mathrm{C}\right)$ and refrigerant state $\left(T_{\text {sat }}=32{ }^{\circ} \mathrm{C}, T=30^{\circ} \mathrm{C}\right)$ before the $\mathrm{EXV}$, while the inlet water temperature is kept at $25^{\circ} \mathrm{C}$. Both the refrigerant mass flux and the water flow rate are factors of the experimental design, as well as the cycle time for the pulsating flow experiments, and varied from (41 to 167) $\mathrm{kg} / \mathrm{m}^{2} \mathrm{~s},(0.10$ to 0.76$) \mathrm{L} / \mathrm{min}$ and (1 to 9$) \mathrm{s}$, respectively. Figure 4 shows the experimental design for the continuous flow experiments.

Figure 4

Figure 5

The central composite design (CCD) is adopted and stretched according to the energy balance between the two heat-exchanging fluids. We strived to cover most of the region before full evaporation in the experimental design, exemplified in Figure 4 at a water temperature difference of $15 \mathrm{~K}$.

Figure 5 shows both the continuous and the pulsating flow designs, where the continuous flow points are located hypothetically at zero cycle time. Five center points were used for both designs. Additional star points were added at the smallest cycle time $(1 \mathrm{~s})$, since the best performance was anticipated there. All the 
star points were located at an alpha value of 1.33 , which is close to the recommended value by Whitcomb and Anderson (2005). Moreover, 2 and 5 points were replicated to reduce the leverage as recommended by Design Expert 8 (2010). In total 15 points were measured for the continuous flow and 28 points were measured for the pulsating flow. Each of these points resulted in 3 heat transfer coefficients obtained from sub-sections 2 to 4 , i.e. 45 heat transfer coefficients for the continuous flow and 84 heat transfer coefficients for the pulsating flow.

\section{Results}

In this section, the heat transfer coefficients with and without flow pulsation are compared with two approaches: the first is a direct comparison of each experimental run while the second is a statistical analysis using response surface methodology. Both methods deal in different ways with the challenge that vapor quality and heat flux are interdependent and simultaneous outputs from the current measurements, which makes it difficult to evaluate the obtained heat transfer coefficients consistently at equal vapor quality and heat flux. Furthermore, visualizations with high-speed camera are presented that illustrates both pros and cons regarding the pulsations. Firstly, the effects of heat flux, mass flux and vapor quality are analyzed and the predicted heat transfer coefficients are compared with flow boiling correlations in the literature for the continuous flow measurements.

\section{Continuous flow measurements}

Figure 6 shows the heat transfer coefficients vs. heat flux at various mass fluxes. Both the reduced values and the uncertainty bars are indicated. The figure demonstrates that the heat transfer coefficient is a weak function of mass flux and a strong function of heat flux for the current experiments. This is often interpreted as indicating that nucleate boiling is the dominating mechanism. Furthermore, the power relation of the lowest mass flux tests $\left(G \leq 50 \mathrm{~kg} / \mathrm{m}^{2} \mathrm{~s}\right)$ shows that $\alpha \propto q^{0.66}$, which corresponds well with the equation proposed in the VDI Heat Atlas (Verein Deutscher Ingenieure 2010) for nucleate boiling: $n\left(p^{*}\right)=0.8-$ $0.1 \cdot 10^{\left(0.76 p^{*}\right)}=0.68$. Since the convective boiling contribution is low, there may be incentive to augment 
this contribution by flow pulsation. On the other hand, the nucleate boiling may decrease as well due to increased suppression of nucleation by the convection.

Figure 6

The heat transfer coefficients for the continuous two-phase flow experiments are compared with wellknown correlations in the literature in Figure 7. It shows that the current experimental heat transfer coefficients are in good agreement with the correlations, except for the phenomenological correlation by Wojtan et al. (2005). The recently developed correlation by Fang (2013) predicts our results the best; however, it was also specifically developed for R134a in contrast to the others.

Table 2 shows the prediction accuracy of these correlations. The table shows that the correlation by Fang (2013) predicts our results with a MAD of $11 \%$, MRD of $0.3 \%$ and has $82.2 \%$ of the data points within 15 \% deviation. The correlations by Gungor \& Winterton (1986), Shah (1982) and Jung et al. (1989) result in MADs around $25 \%$. The former slightly overpredicts our results (MRD $=7.5 \%$ ) whereas the latter two considerably underpredicts our results (MRD $<-20 \%$ ). More than $50 \%$ of our data are predicted within 25 $\%$ using these correlations. The phenomenological correlation by Wojtan et al. (2005) significantly underpredicts our results $(\mathrm{MRD}=43.2 \%)$ and only $15.6 \%$ of the data points are within $30 \%$ deviation.

Figure 7

Table 2

\section{Direct comparison}

In this section, the local time-averaged heat transfer coefficients are compared directly in sub-sections 2 to 4 as function of the cycle time. The continuous flow results are presented at zero cycle time for simplicity. To account for variations in the controlled parameters, as well as vapor quality and heat flux, the entire set of reduced heat transfer coefficients are normalized by the best predicting correlation from Table 2 (Fang, 2013). The results are shown in Figure 8. The figure indicates not only the comparison of continuous and pulsating flow, but also the prediction accuracy of the Fang (2013) correlation for all our measurements. 
There is a small tendency towards an underestimation at lower mass fluxes and an overestimation at higher mass fluxes. Note that the water temperature decreases through sub-section 4 to 2 , thus the highest heat fluxes are prevalent in sub-section 4 , whereas the smallest heat fluxes are located in sub-section 2 . The results are further normalized by the continuous flow results in Figure 9 to illustrate the improvements of using flow pulsations better.

The heat transfer coefficients change less than expected with the cycle time. On the other hand, there is a tendency towards better heat transfer coefficients as the cycle time approach $1 \mathrm{~s}$ (fastest flow pulsation). For low cycle times ( $1 \mathrm{~s}$ to $2 \mathrm{~s}$ ), the heat transfer coefficients are always greater than the continuous flow (cycle time $=0)$, except for a single point $\left(G=50 \mathrm{~kg} / \mathrm{m}^{2} \mathrm{~s}, \dot{V}_{w}=0.25 \mathrm{~L} / \mathrm{min}\right.$ in sub-section 2). The average enhancement by pulsations is $3.2 \%$ for these cycle times. At higher cycle times the enhancement decreases.

An important reduction in the heat transfer coefficient is observed with flow pulsation at high cycle times and water flow rates and in sub-section 4 , where the water temperature and heat flux are highest $(G=150$ $\mathrm{kg} / \mathrm{m}^{2} \mathrm{~s}, \dot{V}_{w}=0.76 \mathrm{~L} / \mathrm{min}$ and $\left.G=100 \mathrm{~kg} / \mathrm{m}^{2} \mathrm{~s}, \dot{V}_{w}=0.57 \mathrm{~L} / \mathrm{min}\right)$. The heat flux is very high at these conditions $\left(q \geq 35 \mathrm{~kW} / \mathrm{m}^{2}\right)$ beyond those typically encountered in refrigeration and air-conditioning. Moreover, the liquid film on the wall dries out significantly when the valve is closed, thus we indicated these points in Figure 9 by denoting them as "significant dry-out". The meaning is that dry-out happens periodically and shows a significant degradation in the time-averaged heat transfer coefficient. The reduction is as much as $8 \%$ compared with continuous flow. Another important observation is observed at low cycle time $(1 \mathrm{~s})$, low water flow rate $(0.1 \mathrm{~L} / \mathrm{min})$ and a mass flux of $100 \mathrm{~kg} / \mathrm{m}^{2} \mathrm{~s}$ in Figure 8 , where the pulsations show a relatively large improvement in sub-section 2 and 3 . These observations will be visualized in the later visualization section. The average enhancement by pulsations is only $0.5 \%$ for cycle times at $5 \mathrm{~s}$ to $6 \mathrm{~s}$, however, disregarding the "significant dry-out" results, the enhancement is slightly better (1.2\%). The average enhancement for cycle times at $8 \mathrm{~s}$ to $9 \mathrm{~s}$ is negative $(-0.4 \%)$, however, again disregarding the "significant dry-out" results, the enhancement becomes $0.1 \%$.

Figure 8

Figure 9

\section{Statistical analysis}


In this section, the experimental results are compared at equal mass flux and heat flux by employing response surface methodology. Two response surfaces were generated using the full quadratic model for both the continuous and the pulsating flow and transformed using the Box-Cox plot power transform recommendation in Design Expert 8 (2010):

$$
\begin{aligned}
\alpha_{\text {cont }}^{1.23}= & +2103.0+3.9714 G+0.69413 q+2.6110 \mathrm{e}-3 G q \\
& -2.4341 \mathrm{e}-2 G^{2}+1.7448 \mathrm{e}-6 q^{2} \\
\alpha_{\text {puls }}{ }^{0.77}= & +80.509+0.67340 G+2.3052 \mathrm{e}-2 q+7.3014 t_{\text {cyc }} \\
& +3.4412 \mathrm{e}-5 G q-9.9511 \mathrm{e}-3 G t_{\text {cyc }}-6.9404 \mathrm{e}-4 q t_{\text {cyc }} \\
& -1.4793 \mathrm{e}-3 G^{2}-2.3949 \mathrm{e}-7 q^{2}-0.20181 t_{\text {cyc }}{ }^{2}
\end{aligned}
$$

The adjusted coefficient of determination $\left(R_{\mathrm{adj}}{ }^{2}\right)$ became 0.996 and 0.981 for the continuous and pulsating flow response surfaces, respectively, thus sufficient for further comparison. Note that as both vapor quality and heat flux are interdependent in the current experiments, creating a response surface in terms of both $x$ and $q$ is not possible using the current test rig and more test sections in series would be needed to establish such a surface with independent vapor quality and heat flux. The heat flux is chosen over vapor quality, because the experiments indicated what is commonly interpreted as nucleate boiling dominance without significant dependency on mass flux (or vapor quality). The analysis of variance (ANOVA) for each responses may be found in Kærn (2016) and shows that the linear cycle time term and the interaction with the heat flux in Equation 8 are statistically significant based on the typical $5 \%$ significance level. Whether this cycle time significance is the improvement or the reduction in the heat transfer performance found in previous section is not yet known, however, the confidence intervals in Figure 10 provides this information. Figure 10a shows the response surfaces compared at equal heat fluxes vs. refrigerant mass flux including the confidence intervals, while Figure 10b shows the normalization based on the continuous flow response.

With overlapping confidence intervals, we would need to accept the null hypothesis (insignificant effect). This is the case for the low heat flux measurements. It does not mean there is no effect of flow pulsations at low heat flux, but only that the effect cannot be verified based on these measurements. More measurements need to be carried out in that region, possibly considering a smaller local volume of the experimental design. At higher heat flux and mass flux, the confidence intervals tend towards no overlaps and we may reject the null hypothesis, i.e. the flow pulsations are statistically significant for the 
improvements at $1 \mathrm{~s}$ cycle time disregarding the low heat flux measurements. Similarly, the reductions at high cycle time and heat flux are statistically significant too.

Figure 10

\section{Visualization}

The flow pulsations are visualized upon opening and closing of the flow modulating EXV and compared to visualizations of continuous flow. The visualizations show the liquid injection immediately after the EXV (before the test section) and after the test section. They are recorded by Photron FastCam-X1280PCI at 1000 fps and 1/16000 s shutter time. The frames are nearly $90 \mathrm{~mm}$ wide and resolved by 960 pixels.

To eliminate time delays between the TTL trigger signal for the high-speed camera and the valve opening/closing, a DC coil was used for the valve together with an optocoupler for generating the TTL trigger signal. The signal was also acquired in Labview and showed time delays smaller than $10 \mathrm{~ms}$ compared with the immediate pressure change after the EXV. Figure 11 to 14 show the visualizations at two different conditions $\left(G=100 \mathrm{~kg} / \mathrm{m}^{2} \mathrm{~s}, \dot{V}_{w}=0.30 \mathrm{~L} / \mathrm{min}\right.$ and $\left.G=150 \mathrm{~kg} / \mathrm{m}^{2} \mathrm{~s}, \dot{V}_{w}=0.76 \mathrm{~L} / \mathrm{min}\right)$ with both $5 \mathrm{~s}$ cycle time for the flow pulsations. The former condition is at the center of our experimental design, while the latter is at higher mass flux and total heat inflow to the test section (high water volume flow), for which "significant dry-out" occurred, as defined in the previous section and shown in sub-section 4 , where the heat flux is highest. Figure 15 shows the full cycling at $1 \mathrm{~s}$ cycle time $\left(G=100 \mathrm{~kg} / \mathrm{m}^{2} \mathrm{~s}\right.$ and $\left.\dot{V}_{w}=0.10 \mathrm{~L} / \mathrm{min}\right)$.

\section{Visualization immediately after the EXV}

The visualizations of the flow upon an opening of the EXV are shown in Figure 11 immediately after the EXV. These visualizations are very similar. For both conditions, a very stagnant liquid film occupies the bottom of the tube before the valve opens. As the valve opens, mist flow occurs in the vapor due to flashing through the EXV while waves are formed on the liquid interface due to shear and drag the liquid downstream. We choose to denote these flow regimes as stratified (S) and stratified-wavy (SW) depending on the amount and size of waves on the stratified interface, and even though liquid droplets are entrained in the vapor. Visualization of flow regimes are always subject to the researchers' own interpretation and further obscured 
by its inherent probabilistic nature and, in the current case, developing flow, which complicate the determination. Annular flow (A) eventually occurs at around $0.2 \mathrm{~s}$ and onwards, i.e. developed annular twophase flow. Annular flow is characterized by a liquid film wetting the whole inner tube surface. The flow regime seems to happen slightly earlier for the high mass flux condition. Notice that the annular flow regime is not always expected at these vapor qualities $(x \sim 0.18)$, for example, the transition to annular flow is predicted at $x \sim 0.31$ in the flow regime based correlation by Wojtan et al. (2005). On the other hand, it is impossible to build up slugs immediately after the expansion valve. Stratified-wavy flow with droplets entrained in the vapor is shown for the continuous flow with larger wavy character at higher mass flux.

The visualization of the flow upon a closing of the EXV are shown in Figure 12 at the same location. The developed annular flow regime prevails until about $0.1 \mathrm{~s}$ as stratification occurs. Again, the two conditions show very similar visualizations. Moreover, their differences are due to the opening degree (opening time over cycle time), which is larger at the higher mass flux condition. Moreover, the flow develops fast immediately after the EXV for both the opening and closing of the EXV. The images of the continuous flows are the same as in Figure 11, but added as a reference to the reader.

\section{Visualization after the test section}

The visualization of the flow upon an opening of the EXV is shown in Figure 13 after the evaporator test section. These visualizations are much different. The amount of liquid at the bottom of the tube as the valve opens is larger at lower water flows compared with higher water flows. More liquid is essentially evaporated from the test section at higher water flows when the valve is closed, due to higher total heat inflow to the test section. It means that larger waves are present at low water volume flow as the valve opens, because of the larger liquid amount. The flow develops faster too and becomes developed annular flow at $0.7 \mathrm{~s}$ and onwards. Moreover, the corresponding continuous flow pattern is stratified-wavy, thus giving rise to annular flow intermittently, and suggests an increasing heat transfer performance with flow pulsation.

On the other hand for the high volume flow condition (and heat inflow), the liquid film in the bottom of the tube tends to vanish. We choose to denote this flow regime as dry-out (D), indicating "significant dryout" has occurred, even though mist flow with possible liquid droplets entrained may be a better interpretation of such flow regime. Moreover, the significant dry-out worsens the heat transfer performance compared with 
the corresponding continuous annular flow. For the pulsating flow, the annular liquid film occurs abruptly after $1.4 \mathrm{~s}$ and wets the inner tube wall again. It means twice as long time to reach annular flow for the higher water flow condition than for the lower water flow condition.

Figure 14 shows the visualization of the flow upon a closing of the EXV at the same location. Note that the determination of the annular to stratified-wavy flow transition is especially difficult for these images. Nonetheless, the annular flow regime prevails for a longer period after the EXV is closed for the case with higher water flow. More liquid is evaporated from the test section, generating more vapor that travels with higher velocities, and sustains the liquid film. For the high water flow condition, the stratified-wavy flow occurs at $0.6 \mathrm{~s}$ and onwards. On the other hand, for the low water flow condition, the stratified-wavy flow occurs at $0.2 \mathrm{~s}$ and onwards. Larger wavy character is shown for the higher water flow condition, consistent with the larger evaporation in the test section mentioned above.

Figure 11

Figure 12

Figure 13

Figure 14

\section{Visualization at 1 s cycling}

Figure 15 shows the full cycling for the condition with relative large heat transfer enhancement due to pulsations ( $t_{\mathrm{cyc}}=1 \mathrm{~s}, G=100 \mathrm{~kg} / \mathrm{m}^{2} \mathrm{~s}$ and $\dot{V}_{w}=0.10 \mathrm{~L} / \mathrm{min}$ ) before and after the test section. Consistent with the previous section, the pulsating flow shows intermittent annular flow both before and after the test section, in an otherwise stratified wavy continuous flow. The full wetting occurs every second for about 0.3 seconds, i.e. much more intermittent wetting than with a $5 \mathrm{~s}$ cycle time. It suggests and explains the relatively larger heat transfer increase with flow pulsations in this condition. Visualizations at $G \leq 50 \mathrm{~kg} / \mathrm{m}^{2} \mathrm{~s}$ and low cycle time did not indicate intermittent annular flow.

Figure 15 


\section{Discussion}

The experimental uncertainty of the predicted heat transfer coefficients was found to be $3.8 \%$, when disregarding the results lower than $2 \mathrm{~kW} / \mathrm{m}^{2} \mathrm{~K}$, while the heat transfer enhancements were lower on average $(3.2 \%)$ at low cycle times ( $1 \mathrm{~s}$ to $2 \mathrm{~s})$ in the direct comparison. At higher cycle times, the performance was shown to be similar for both continuous and pulsating flow. Only, at very high heat flux and cycle times, the liquid film dries out significantly when the valve is closed, and results in a significant decrease in the heat transfer coefficient. On the other hand, the statistical analysis revealed that the effect of the cycle time was indeed statistically significant (based on the $5 \%$ significance level) regarding both the improvements and the reductions in the flow boiling heat transfer coefficient, when disregarding the lowest heat flux measurements. Hence, the effect of the flow pulsations are not great but verified. Furthermore, we demonstrated by visualization that the annular flow could occur intermittently due to pulsations in an otherwise stratifiedwavy continuous flow, which suggests an increase in the flow boiling heat transfer performance.

It is interesting to note the tendency towards higher improvements by pulsations as the mass flux increases, as indicated in Figure 10. This is in contrast to what was expected before the tests were performed, i.e. that the low mass flux conditions with nucleate boiling dominance would benefit by the increased convection due to the flow pulsations. Apparently, the results indicate that the improvements are higher when the convective contribution is higher too, i.e. at higher refrigerant mass flux. Moreover, the effect of subcooling with and without flow pulsations is something not investigated yet as well as other fluids, mixtures, pressures before and after the expansion valve, hydraulic diameter etc. In the light of the many factors that may show more or less effect on the heat transfer coefficient, the results from this analysis should be viewed as indications, noting that the investigation was considering the location immediately downstream the expansion valve. In other words, the hypothesis that flow pulsations increase flow boiling heat transfer, remains open seen from the general perspective. The possible improvement in the time-averaged heat transfer coefficient was small with flow pulsations. Compared with other flow boiling heat transfer enhancement techniques, it does not seem as promising. For example, micro-fin tubes with numerous $(\sim 70)$ low height ( $\sim 0.15 \mathrm{~mm})$, spiraling ( $\sim 18 \mathrm{deg}$.) fins improve the heat transfer coefficient by as much as $50 \%$ to $100 \%$ (Bergles 2003), however, the combination with flow pulsations might boost the improvements even more. 
It is common practice for horizontal flow boiling in traditional size tubing to measure wall temperatures at least with 4 locations circumferentially. However, given our future research activities on extending the test section to cover the full evaporation region, and test effects of flow pulsation further downstream the evaporator, we reduced the number of wall thermocouples so far. The next version of the test sections will include 4 wall temperatures circumferentially. It might show an effect on the actual values of the heat transfer coefficient, but their comparison (pulsation vs. continuous flow) is believed to give similar results.

\section{Conclusion}

This paper presents an experimental comparison of flow boiling heat transfer in a water-heated $8 \mathrm{~mm}$ round tube with and without fluid flow pulsation for R134a, i.e. using a flow modulating expansion valve and a stepper motor continuous flow expansion valve. The mass flux ranged from $41 \mathrm{~kg} / \mathrm{m}^{2} \mathrm{~s}$ to $167 \mathrm{~kg} / \mathrm{m}^{2} \mathrm{~s}$, vapor quality from 0.18 to 0.59 and heat flux from $1.5 \mathrm{~kW} / \mathrm{m}^{2}$ to $45 \mathrm{~kW} / \mathrm{m}^{2}$. For these conditions, the heat transfer coefficients were primarily dependent on heat flux, which is often interpreted as indicating that nucleate boiling is the dominating mechanism. Moreover, it was found that the flow pulsations improve the heat transfer coefficient by $3.2 \%$ on average at low cycle times ( $1 \mathrm{~s}$ to $2 \mathrm{~s})$. However, at higher cycle times ( $5 \mathrm{~s}$ to $9 \mathrm{~s}$ ) the performance is much similar to that of continuous flow boiling. If the cycle time and the heat flux are high $\left(q \geq 35 \mathrm{~kW} / \mathrm{m}^{2}\right)$, the flow pulsations may result in dry-out of the liquid film and consequently lower time-averaged heat transfer coefficient, i.e. as much as $8 \%$.

Even though the heat transfer improvement and reductions are small, it was found that the effect of the flow pulsations was statistically significant based on the $5 \%$ significance level, when disregarding the lowest heat flux measurements. 


\section{Nomenclature}

$\begin{array}{ll}d & \text { inner tube diameter, } \mathrm{m} \\ D & \text { outer tube diameter, } \mathrm{m} \\ G & \text { mass flux, } \mathrm{kg} / \mathrm{m}^{2} \mathrm{~s} \\ h & \text { specific enthalpy, } \mathrm{J} / \mathrm{kg} \\ k & \text { thermal conductivity, } \mathrm{W} / \mathrm{mK} \\ q & \text { heat flux, } \mathrm{W} / \mathrm{m}^{2} \\ R & \text { coefficient of determination, - } \\ t_{\text {cyc }} & \text { cycle time, } \mathrm{s} \\ T & \text { temperature, }{ }^{\circ} \mathrm{C} \\ \dot{V} & \text { volume flow rate, } \mathrm{L} / \mathrm{min} \\ x & \text { vapor quality, - } \\ \alpha & \text { axial coordinate, } \mathrm{m} \\ \alpha & \text { heat transfer coefficient, } \mathrm{W} / \mathrm{m}^{2} \mathrm{~K} \\ \rho & \text { density, } \mathrm{kg} / \mathrm{m}^{3}\end{array}$

\section{Subscripts and abbreviations}

$\begin{array}{ll}\text { adj } & \text { adjusted } \\ \text { cont } & \text { continuous } \\ \text { exp } & \text { experimental } \\ \text { in } & \text { inlet } \\ \text { pred } & \text { predicted } \\ \text { puls } & \text { pulsating } \\ \text { sat } & \text { saturation } \\ \text { w } & \text { water } \\ \text { wall } & \text { wall } \\ \infty & \text { ambient }\end{array}$




\section{EXV expansion valve}

MAD mean average deviation

MRD mean relative deviation 


\section{References}

Antonenko, V.A., Chistyakov, Y.G. \& Kudritskiy, G.R., 1992. Vibration-aided boiling heat transfer. Heat Transfer Research, 24(8), pp.1147-1151.

Bergles, A.E., 2003. High-flux processes through enhanced heat transfer. In Rohsenow symposium on future trends in heat transfer. Massachusetts, USA.

Bohdal, T. \& Kuczyński, W., 2005. Investigation of Boiling of Refrigeration Medium Under Periodic Disturbance Conditions. Experimental Heat Transfer, 18(3), pp.135-151.

Chen, C.A., Chang, W.R. \& Lin, T.F., 2010. Time periodic flow boiling heat transfer of R-134a and associated bubble characteristics in a narrow annular duct due to flow rate oscillation. International Journal of Heat and Mass Transfer, 53(19-20), pp.3593-3606.

Design Expert 8, 2010. Stat-Ease Inc., version 8.0.6, URL www.statease.com.

Fang, X., 2013. A new correlation of flow boiling heat transfer coefficients based on R134a data. International Journal of Heat and Mass Transfer, 66, pp.279-283.

Gnielinski, V., 1976. New equation for heat and mass transfer in turbulent pipe and channel flow. International Chemical Engineering, 16, pp.359-368.

Gungor, K.E. \& Winterton, R.H.S., 1986. A general correlation for flow boiling in tubes and annuli. International Journal of Heat and Mass Transfer, 29, pp.351-358.

Jung, D.S. et al., 1989. A study of flow boiling heat transfer with refrigerant mixtures. International Journal of Heat and Mass Transfer, 32(9), pp.1751-1764.

Kline, S.J. \& McClintock, F.A., 1953. Describing uncertainties in Single-Sample experiments. Mechanical Engineering, 75(1), pp.3-8.

Kuczyski, W., Charun, H. \& Bohdal, T., 2012. Influence of hydrodynamic instability on the heat transfer coefficient during condensation of R134a and R404A refrigerants in pipe mini-channels. International Journal of Heat and Mass Transfer, 55(4), pp.1083-1094.

Kærn, M.R., 2016. Continuous vs. pulsating flow boiling. Part 2: Statistical comparison using response surface methodology. Proceedings of the 16th International Refrigeration and Air Conditioning Conference.

Obinelo, I.F., Round, G.F. \& Chang, J.S., 1994. Condensation enhancement by steam pulsation in a reflux condenser. International Journal of Heat and Fluid Flow, 15(1), pp.20-29.

Ohadi, M.M. et al., 1996. Active Augmentation of Single-Phase and Phase-Change Heat Transfer - an overview. In R. M. Manglik \& A. D. Kraus, eds. Process, Enhanced, and Multiphase Heat Transfer. New York, USA: Begell House, pp. 277-286.

Roh, C.W. \& Kim, M.S., 2012. Enhancement of heat pump performance by pulsation of refrigerant flow using a solenoid-driven control valve. International Journal of Refrigeration, 35(6), pp.1547-1557.

Ruspini, L.C., Marcel, C.P. \& Clausse, A., 2014. Two-phase flow instabilities: A review. International Journal of Heat and Mass Transfer, 71, pp.521-548.

Shah, M.M., 1982. Chart correlation for saturated boiling heat transfer: Equations and further study. ASHRAE Transactions, 88, pp.185-196.

Verein Deutscher Ingenieure, 2010. VDI Heat Atlas 2nd ed., Springer-Verlag Berlin Heidelberg, (English version).

Wedekind, G.L., 1971. An experimental investigation into the oscillatory motion of the mixture-vapor transition point in horizontal evaporating flow. Transactions of the ASME. Series C, Journal of Heat Transfer, 93(1), pp.47-54.

Whitcomb, P.J. \& Anderson, M.J., 2005. RSM Simplified: Optimizing Processes Using Response Surface Methods for Design of Experiments, CRC Press, Taylor \& Francis Group.

Wojtan, L., Ursenbacher, T. \& Thome, J.R., 2005. Investigation of flow boiling in horizontal tubes: Part II-Development of a new heat transfer model for stratified-wavy, dryout and mist flow regimes. International Journal of Heat and Mass Transfer, 48(14), pp.2970-2985. 


\section{Acknowledgement}

This research was supported by the Danish Council for Independent Research | Technology and Innovation, (11-117025). 


\begin{tabular}{|l|c|c|c|}
\hline Table 1. Range and uncertainty of reduced variables \\
\hline Variables & Range & $\begin{array}{c}\text { Relative } \\
\text { uncertainty, } \%\end{array}$ & $\begin{array}{c}\text { Absolute } \\
\text { uncertainty }\end{array}$ \\
\hline Heat flux, $\mathrm{kW} / \mathrm{m}^{2}$ & $1.540-44.954$ & $0.83-9.57$ & $0.141-0.390$ \\
\hline Vapor quality & $0.18-0.59$ & $0.63-3.33$ & $0.0011-0.0060$ \\
\hline Heat transfer coefficient, $\mathrm{kW} / \mathrm{m}^{2} \mathrm{~K}$ & $0.531-7.327$ & $1.78-10.28$ & $0.054-0.143$ \\
\hline
\end{tabular}

\begin{tabular}{|c|c|c|c|c|c|c|}
\hline \multirow[t]{2}{*}{ Correlation } & \multirow[t]{2}{*}{$\begin{array}{l}\text { MAD } \\
(\%)\end{array}$} & \multirow[t]{2}{*}{$\begin{array}{c}\text { MRD } \\
(\%)\end{array}$} & \multicolumn{4}{|c|}{$\begin{array}{l}\text { Percentile of data points within the given } \\
\text { absolute relative deviation }(\%)\end{array}$} \\
\hline & & & $\pm 15 \%$ & $\pm 20 \%$ & $\pm 25 \%$ & $\pm 30 \%$ \\
\hline Gungor \& Winterton (1986) & 25.9 & 7.5 & 31.1 & 35.6 & 53.3 & 64.4 \\
\hline Shah (1982) & 26.2 & -24.7 & 20.0 & 31.1 & 51.1 & 60.0 \\
\hline Jung et al. (1989) & 23.7 & -20.4 & 17.8 & 33.3 & 57.8 & 82.2 \\
\hline Wojtan et al. (2005) & 44.3 & -43.2 & 2.2 & 6.7 & 8.9 & 15.6 \\
\hline Fang (2013) & 10.9 & 0.3 & 82.2 & 88.9 & 88.9 & 95.6 \\
\hline
\end{tabular}




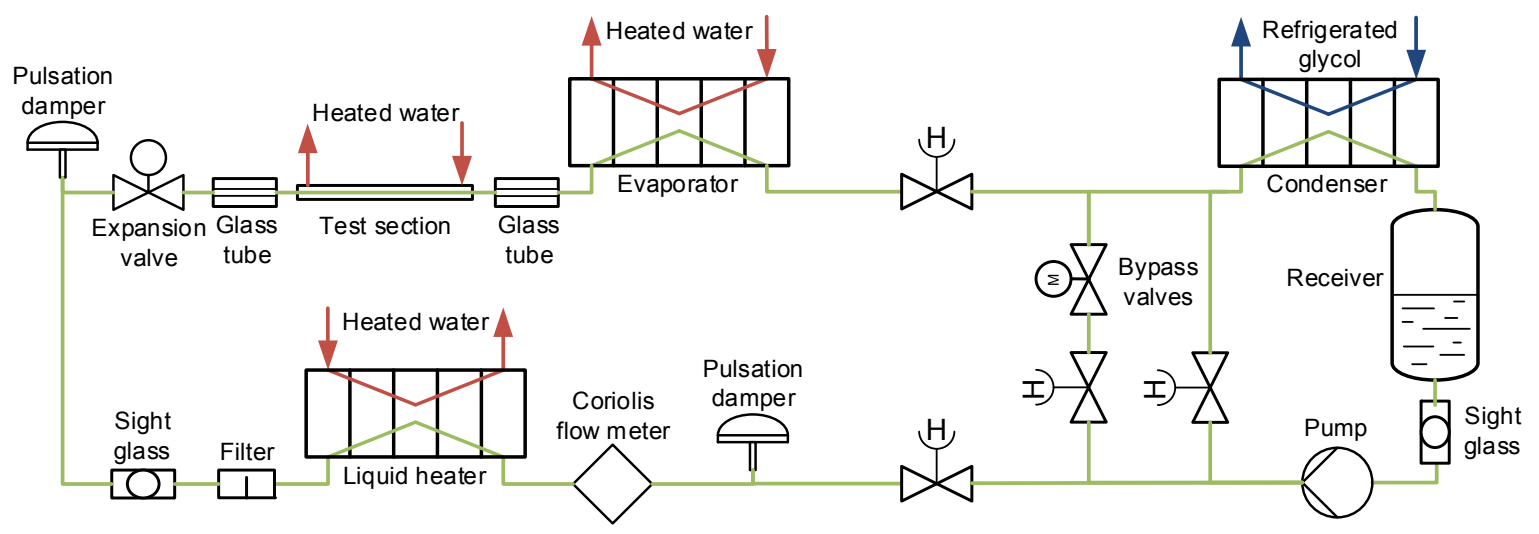

Figure 1: Experimental apparatus (H: hand-operated valve)

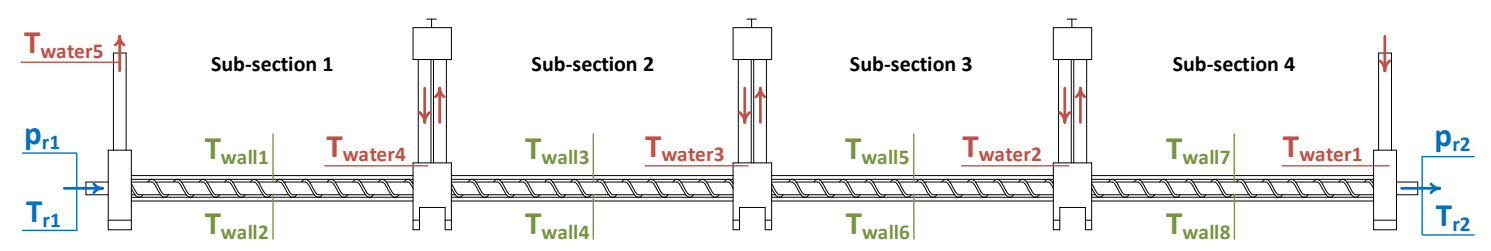

Figure 2: Test section including each sub-section

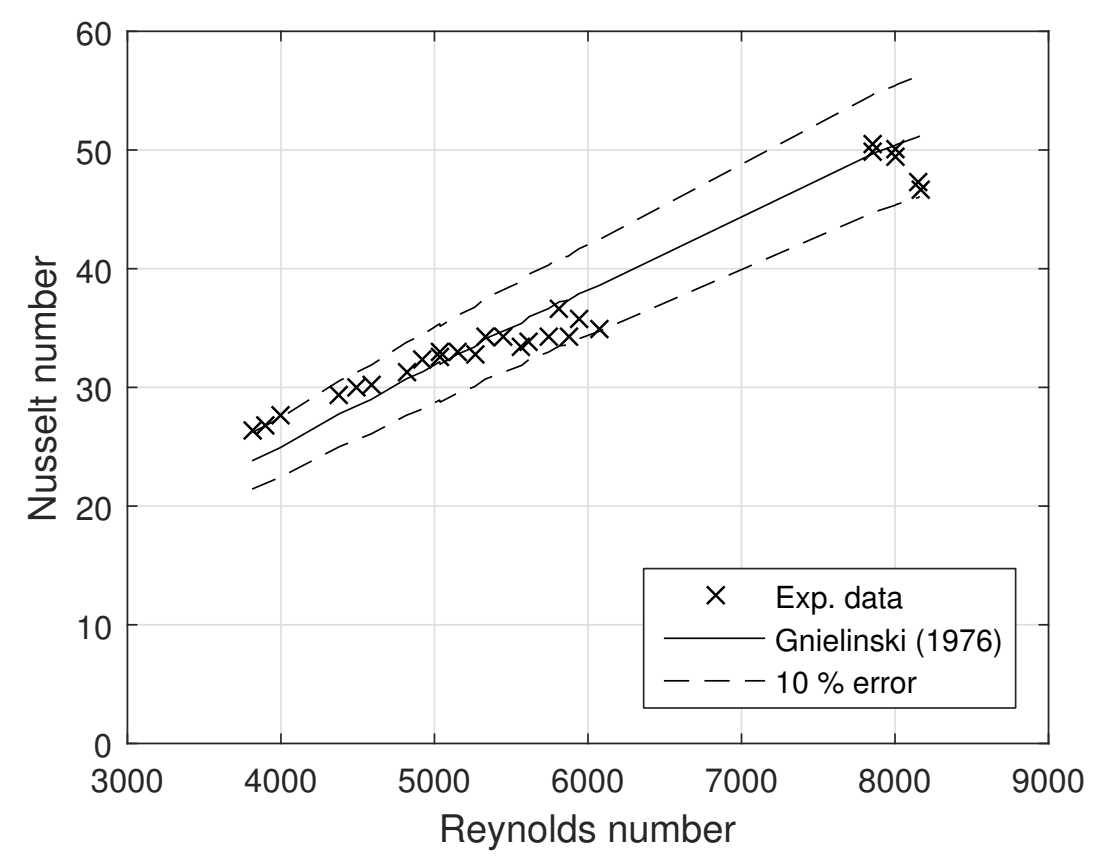

Figure 3: Single-phase liquid Nusselt numbers vs. liquid Reynolds number 


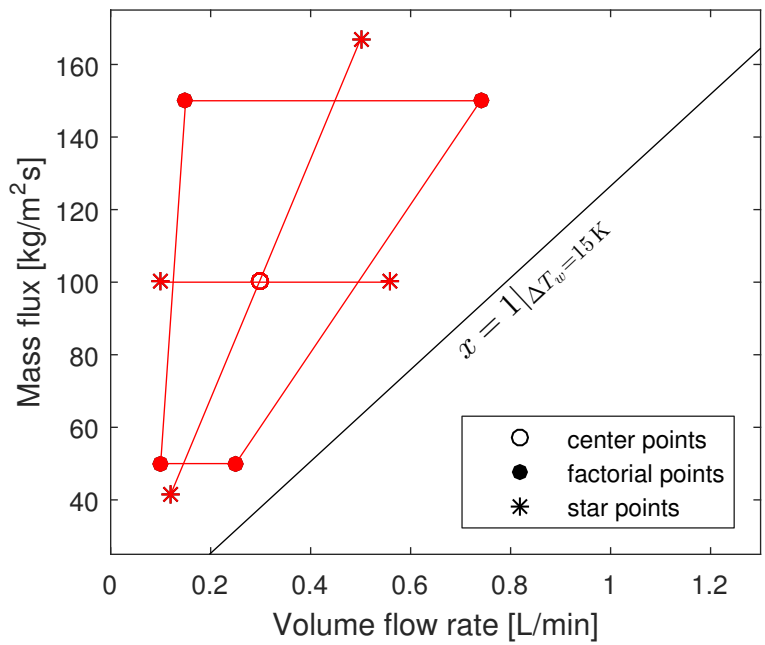

Figure 4: Experimental design for continuous flow

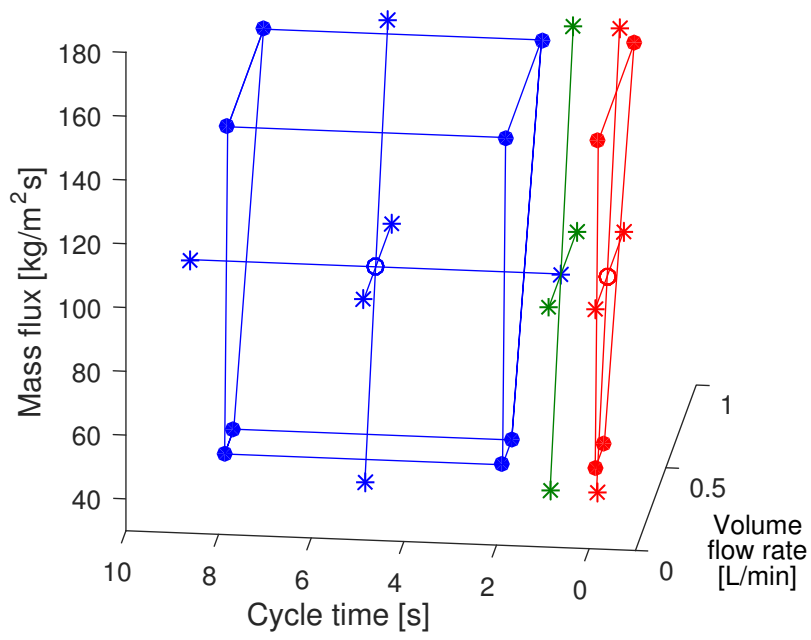

Figure 5: Full experimental design for continuous and pulsating flow 


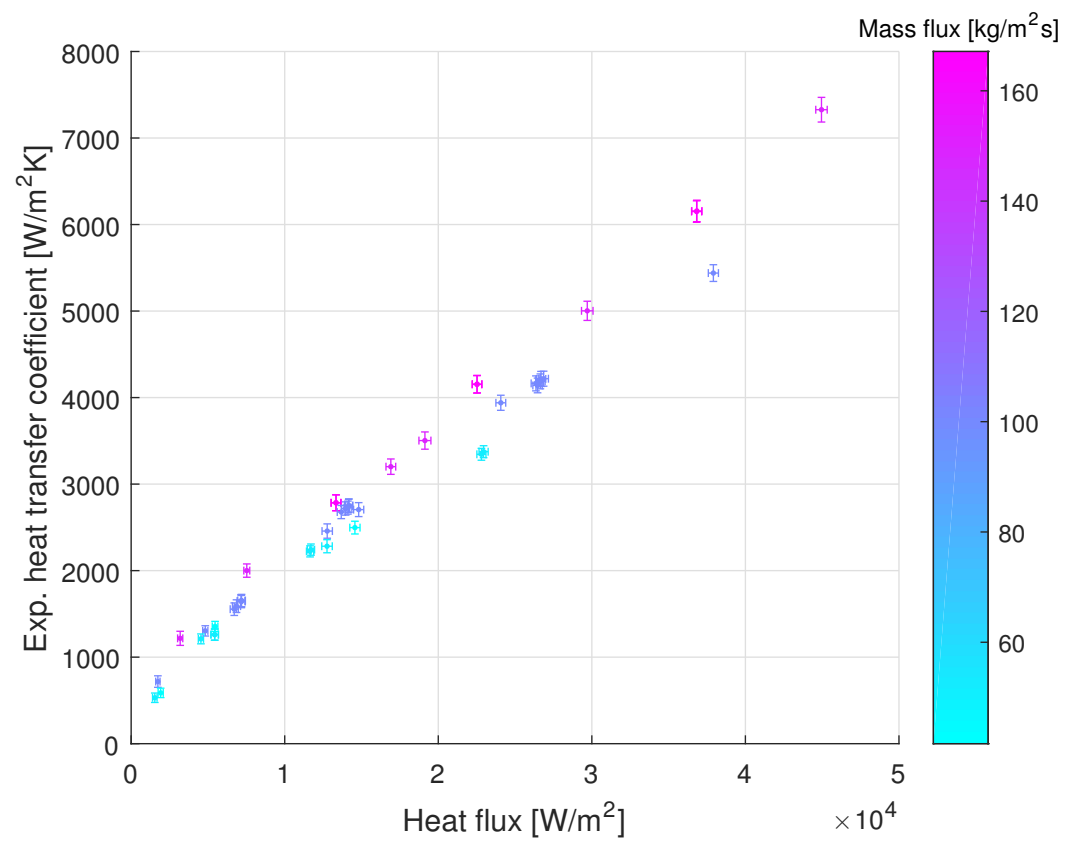

Figure 6: Experimental heat transfer coefficients vs. heat flux at various mass fluxes for the continuous flow experiments

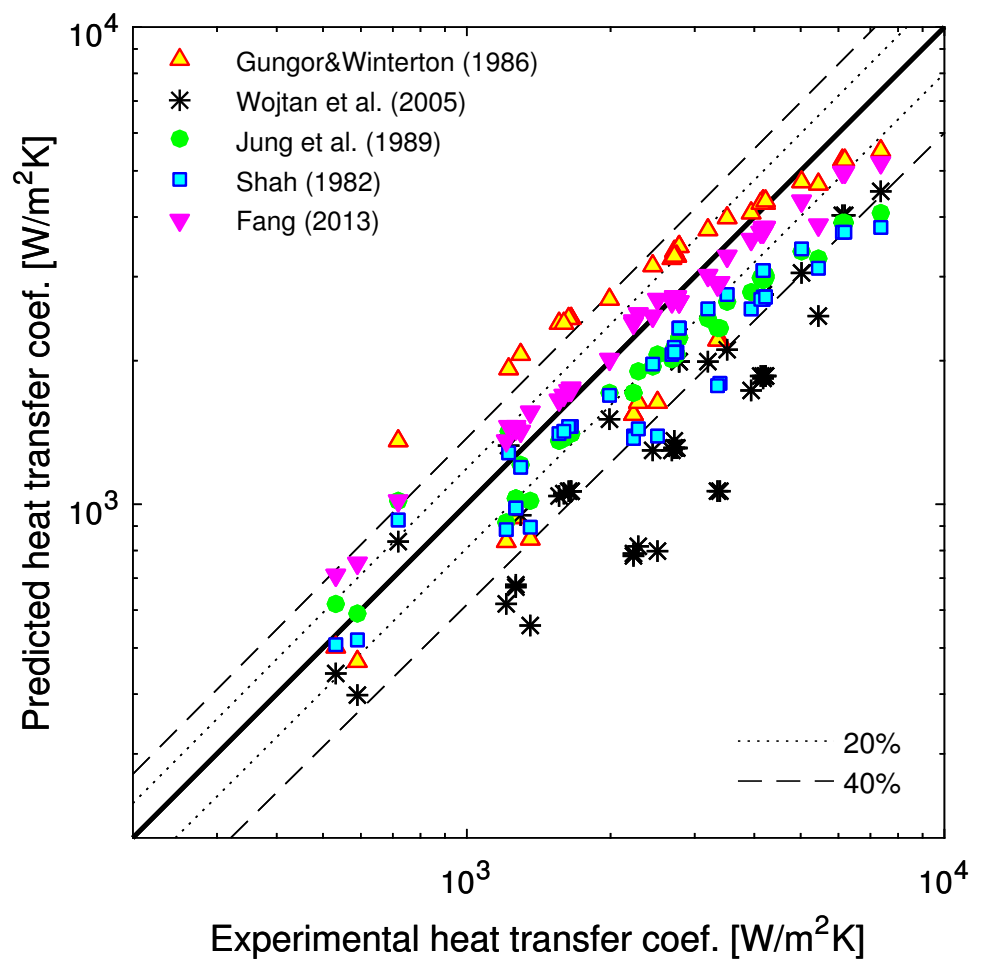

Figure 7: Parity plot of correlated heat transfer coefficients and measured heat transfer coefficients for the continuous flow experiments 


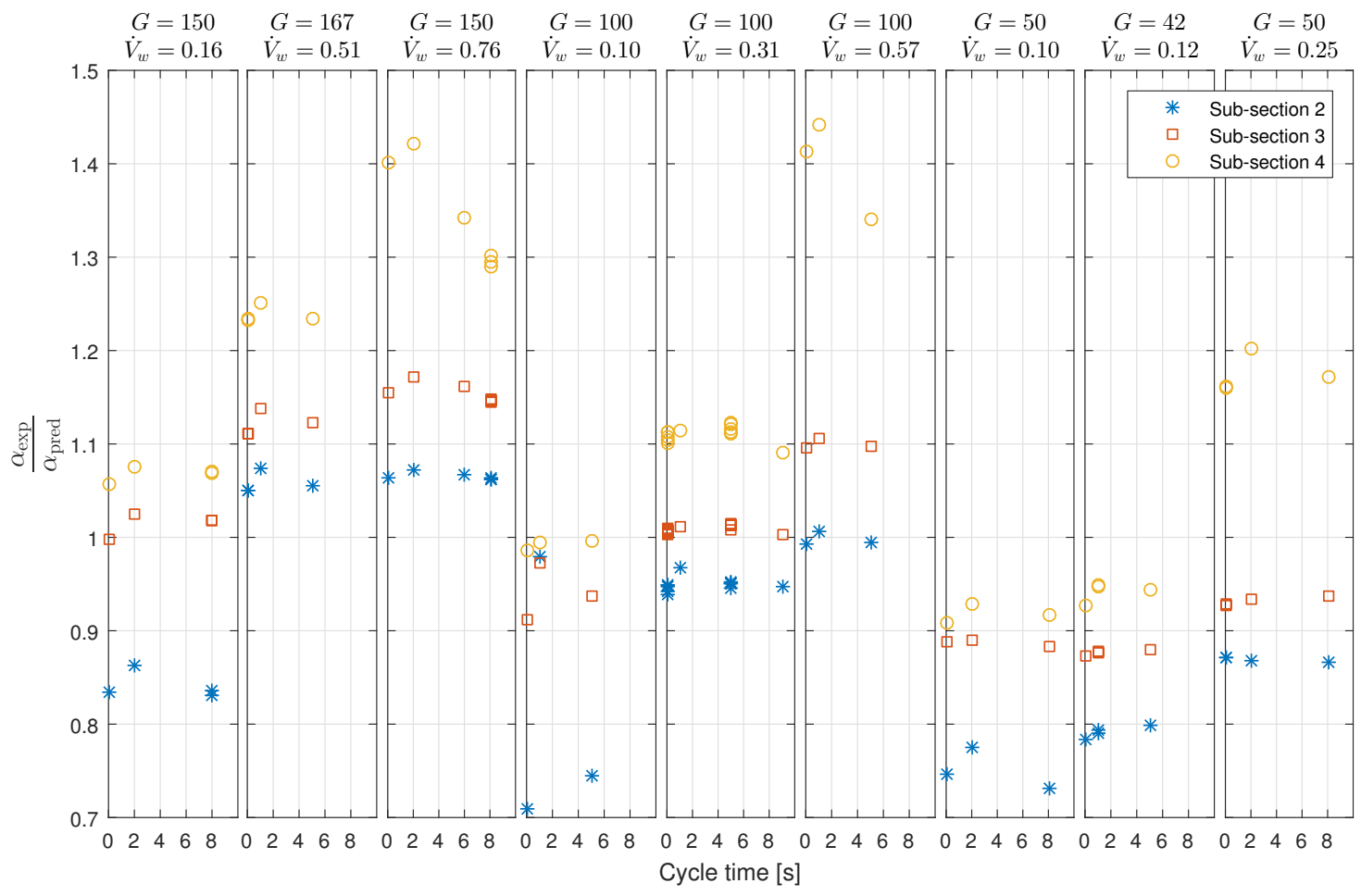

Figure 8: Normalized heat transfer coefficients calculated by the Fang (2013) correlation vs. cycle time at various refrigerant mass fluxes and water volume flows. Continuous flow results are located at 0 cycle time.

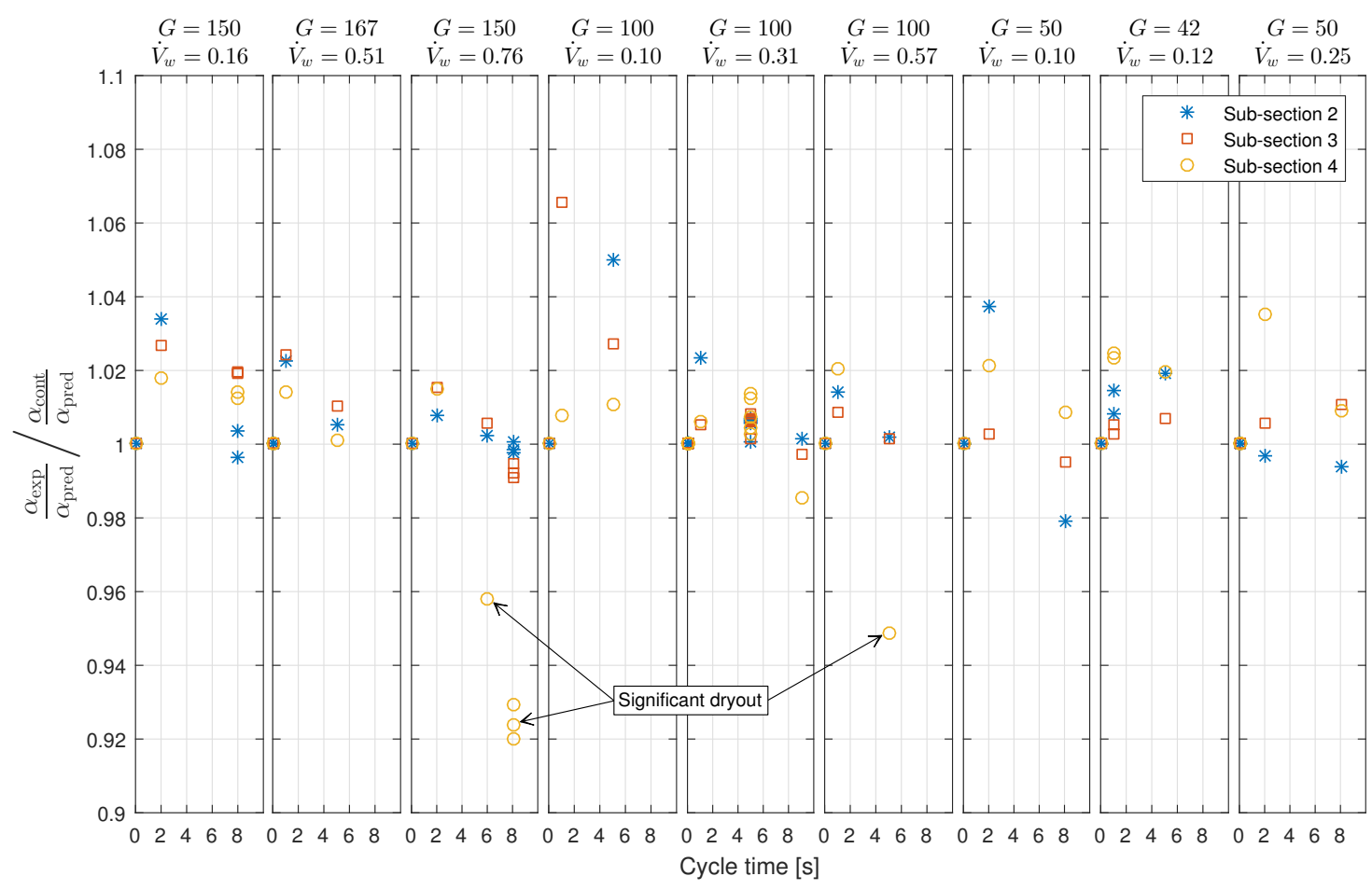

Figure 9: Normalized heat transfer coefficients calculated by the Fang (2013) correlation (and the continuous flow results) vs. cycle time at various refrigerant mass fluxes and water volume flows. Continuous flow results are located at 0 cycle time. 
a
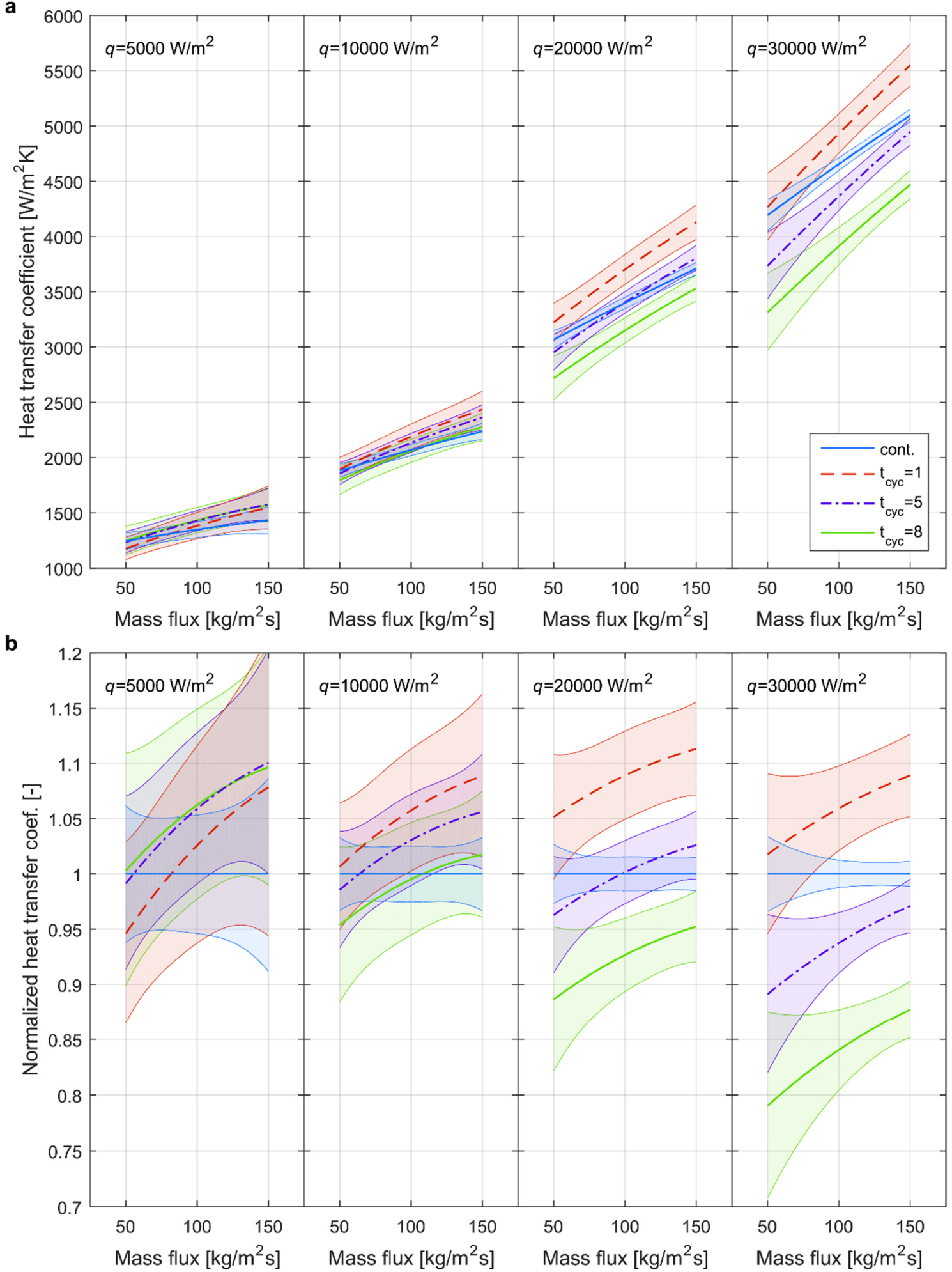

Figure 10: Heat transfer response (a) and normalized heat transfer response based on continuous flow response (b). Thick lines represent the response; thin lines represent confidence intervals. 


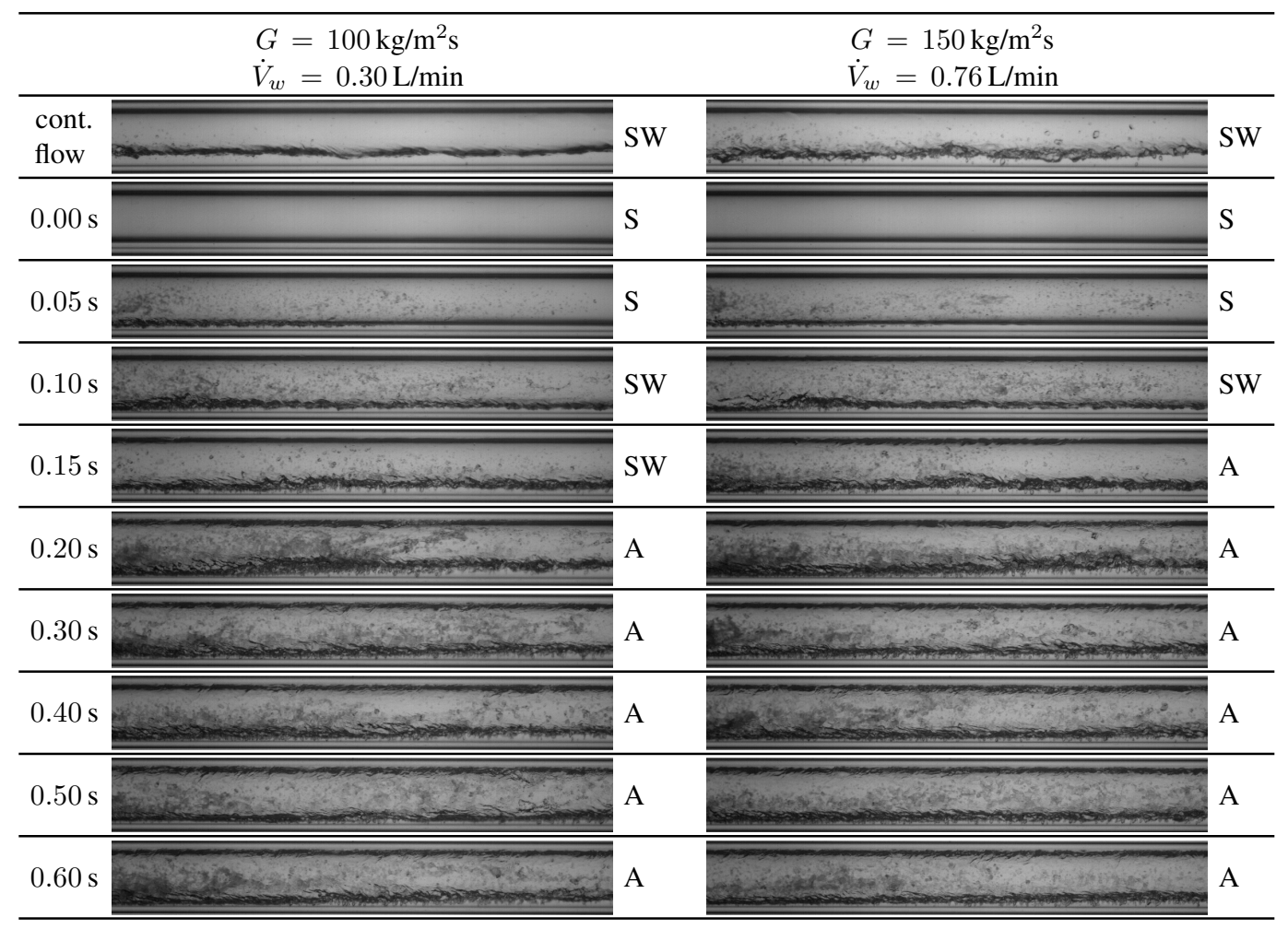

Figure 11: Visualization of continuous and pulsating flow (valve opening) immediately after the EXVs

\begin{tabular}{|c|c|c|c|c|}
\hline & $\begin{array}{c}G=100 \mathrm{~kg} / \mathrm{m}^{2} \mathrm{~s} \\
\dot{V}_{w}=0.30 \mathrm{~L} / \mathrm{min}\end{array}$ & & $\begin{array}{l}G=150 \mathrm{~kg} / \mathrm{m}^{2} \mathrm{~s} \\
\dot{V}_{w}=0.76 \mathrm{~L} / \mathrm{min}\end{array}$ & \\
\hline $\begin{array}{l}\text { cont. } \\
\text { flow }\end{array}$ & Sons & SW & 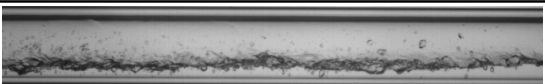 & SW \\
\hline $0.00 \mathrm{~s}$ & 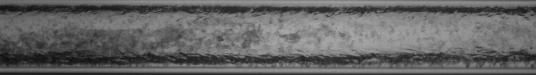 & A & 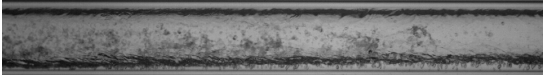 & A \\
\hline $0.05 \mathrm{~s}$ & sens? & A & & A \\
\hline $0.10 \mathrm{~s}$ & 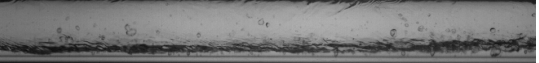 & SW & 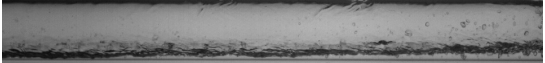 & SW \\
\hline $0.15 \mathrm{~s}$ & $\rightarrow x_{1}$ & SW & 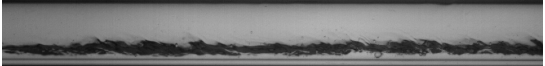 & SW \\
\hline $0.20 \mathrm{~s}$ & & $\mathrm{~S}$ & & $\mathrm{~S}$ \\
\hline $0.30 \mathrm{~s}$ & & $\mathrm{~S}$ & & $\mathrm{~S}$ \\
\hline $0.40 \mathrm{~s}$ & & $S$ & & $\mathrm{~S}$ \\
\hline $0.50 \mathrm{~s}$ & & $\mathrm{~S}$ & & $S$ \\
\hline $0.60 \mathrm{~s}$ & & $S$ & & $S$ \\
\hline
\end{tabular}

Figure 12: Visualization of continuous and pulsating flow (valve closing) immediately after the EXVs 


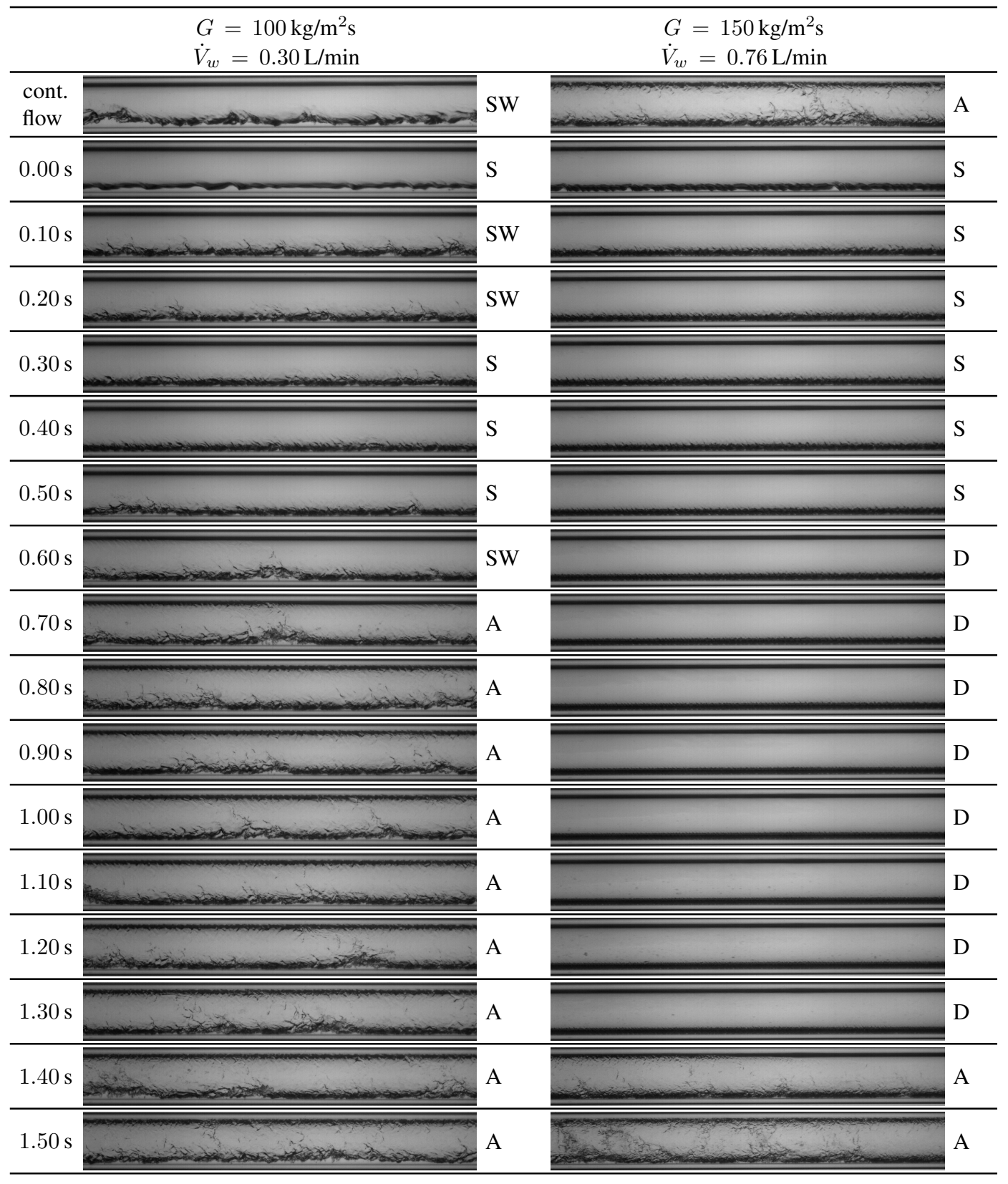

Figure 13: Visualization of continuous and pulsating flow (valve opening) after the test section 


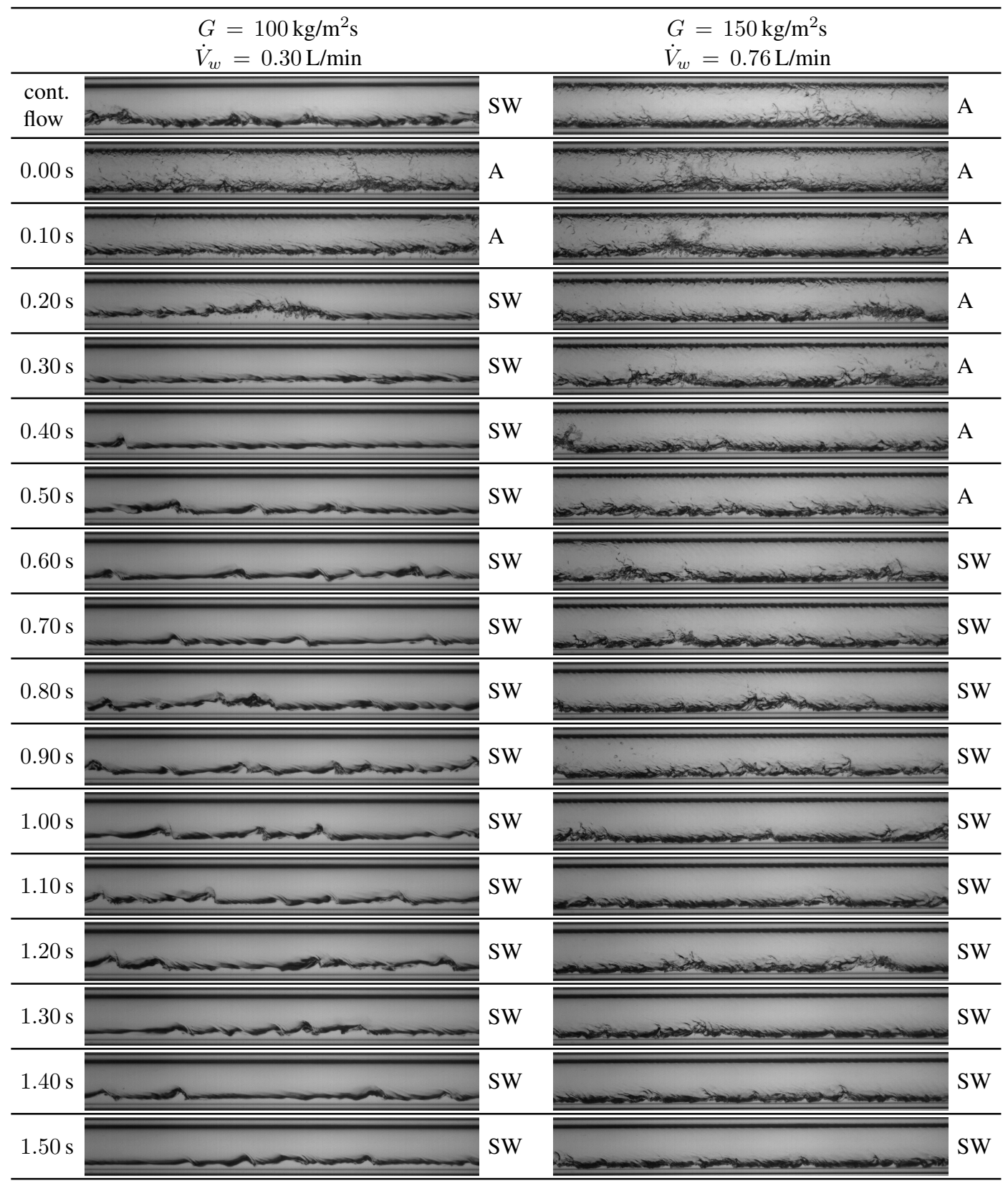

Figure 14: Visualization of continuous and pulsating flow (valve closing) after the test section 


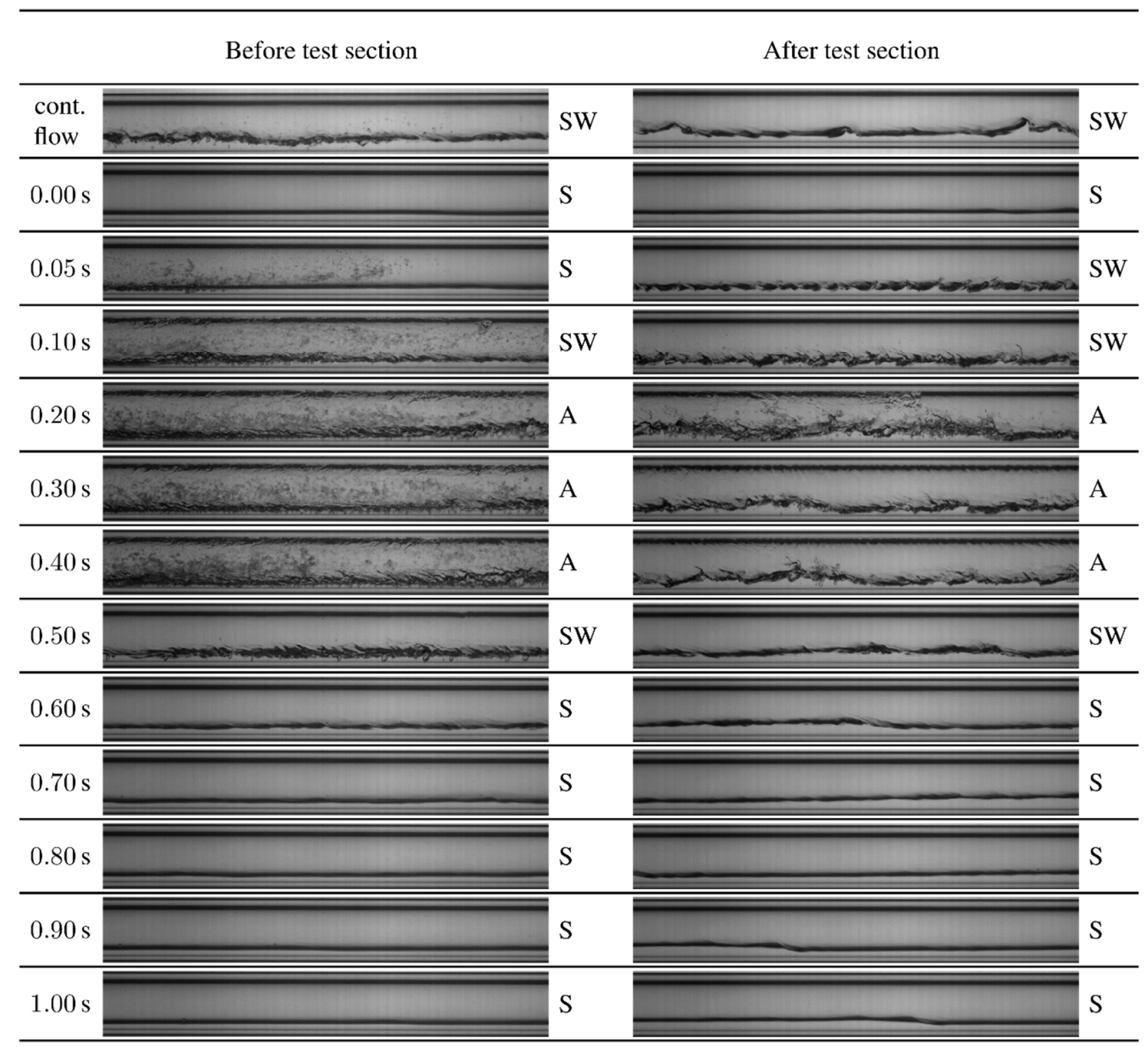

Figure 15: Visualization of continuous and pulsating flow $\left(t_{\mathrm{cyc}}=1\right)$ before and after the test section $\left(G=100 \mathrm{~kg} / \mathrm{m}^{2} \mathrm{~s}, \dot{V}_{w}=0.1 \mathrm{~L} / \mathrm{min}\right)$ 